\title{
Da hipótese de uma adolescentização generalizada e seus desafios para a educação
}

\author{
Jacqueline de Oliveira Moreira \\ Pontifícia Universidade Católica de Minas Gerais - Belo Horizonte - MG - Brasil \\ Nathiéle Araújo Oliveira \\ Pontifícia Universidade Católica de Minas Gerais - Belo Horizonte - MG - Brasil
}

\section{Resumo}

O presente artigo tem como objetivo propor discussões a respeito da hipótese de uma adolescentização generalizada da sociedade enfatizando-se as noções de narcisismo e individualismo enquanto fenômenos sociais - e dos possíveis impasses impostos por este cenário à educação formal. Por meio de uma reflexão teórica de caráter especulativo, o texto delineia-se a partir da psicanálise, com algumas reflexões sobre o encontro entre os dois temas, assim como busca analisar o fenômeno no contexto da contemporaneidade, marcado pelas lógicas sociais do consumo e pelo enfraquecimento dos vínculos geracionais, bem como do vínculo histórico-temporal entre passado e futuro.

Palavras-chave: Adolescência; educação; psicanálise.

\section{From the hypothesis of a generalized adolescence and its challenges to education}

\begin{abstract}
This article aims to propose discussions about the hypothesis of a general adolescence of society emphasizing the notions of narcissism and individualism as social phenomena - and the possible impasses imposed by this scenario on formal education. Through a theoretical reflection of a speculative nature, the text delineates from psychoanalysis, with some reflections on the encounter between the two themes, as well as the search to analyze the phenomenon in the context of contemporaneity, marked by the social logics of consumption and by weakening of generational links, as well as the historical-temporal link between past and future.
\end{abstract}

Keywords: Adolescence; education; psychoanalysis.

\section{La hipótesis de una adolescentización generalizada y sus desafíos para la educación}

\section{Resumen}

En el presente artículo se tuvo el objetivo de proponer discusiones a respecto de la hipótesis de una adolescentización generalizada de la sociedad - en lo que se enfatizan las nociones de narcisismo e individualismo como fenómenos sociales - y de los posibles dilemas de este escenario en la educación formal. Por intermedio de una reflexión teórica de carácter especulativo, el texto se delinea a partir del psicoanálisis con algunas reflexiones sobre el encuentro entre los dos temas, y también se busca analizar el fenómeno en el contexto de la contemporaneidad, marcado por las lógicas sociales del consumo y por el debilitamiento de los vínculos generacionales, así como del vínculo histórico-temporal entre pasado y futuro.

Palabras clave: Adolescencia; educación; psicoanálisis. 


\section{Introdução}

A sociedade contemporânea é marcada por uma forte aceleração nos modos e costumes sociais. O rápido desenvolvimento de tecnologias de mídias, médicas, de produção de bens e outras anunciam a perecibilidade dos produtos. Podemos pensar que vivemos um tempo em que, por não se suportar o produto velho, sempre se investe em um produto novo. Seria necessário sermos sempre jovens para acompanhar as inovações incessantes? O período da juventude e/ou adolescência seria o momento que melhor caracteriza os ideais atuais?

Em certo sentido, pode-se pensar que vivemos em uma época de valorização da adolescência, ou de uma "adolescentização", termo que aparece descrito no famoso livro de Christopher Lasch (1983), A Cultura do Narcisismo:

porque o crescimento e o desenvolvimento pessoais se tornaram tão árduos de ser atingidos; porque o temor de amadurecer e de ficar velho persegue nossa sociedade; porque as relações pessoais se tornaram tão instáveis e precárias; e porque a vida interior já não oferece qualquer refúgio para os perigos que nos envolvem. (Lasch, 1983, p. 37).

A sociedade contemporânea, marcada por um elevado caráter imagético, encontra na dimensão estética valor fundamental. Estetizada, a vida se reduz às imagens, à aparência e às relações sociais.

Por seu caráter narcísico, a cultura pós-moderna apresenta um explícito horror à velhice (Lasch, 1983), o que produz nos sujeitos uma dificuldade de assumir o envelhecimento e seus signos, especialmente o envelhecimento do corpo. Busca-se, assim, um prolongamento da juventude, uma espécie de equiparação do corpo à máquina. $A$ crença de que se pode transformar o corpo em uma espécie de cyborg que impede que se enfrentem as incongruências naturais do corpo "tem subsidiado o imaginário dos indivíduos, incidindo em suas buscas e efetivações de tentativas de um corpo perfeito por meio de cirurgias e do enxerto de substâncias" (Frois, Moreira, \& Stengel, 2011, p.72). A velhice, antes relacionada à maturidade e à sabedoria nas sociedades tradicionais, passa a apontar para a própria precariedade e finitude da vida.

Dessa forma, vivemos uma supervalorização do corpo jovem, como argumenta Kehl (2007):

O adolescente das últimas décadas do século $X X$ deixou de ser a criança grande, desajeitada e inibida, de pele ruim e hábitos antissociais, para se transformar no modelo de beleza, liberdade e sensualidade para todas as outras faixas etárias. O adolescente pós-moderno desfruta de todas as liberdades da vida adulta, mas é poupado de quase todas as responsabilidades (Kehl, 2007, p. 46).

Sabemos que as mídias veiculam a ideia do corpo jovem como o ideal de perfeição. Segundo Maria Lucia Homem (2009), "a expressão latina puer aeternus remete à posição daquele que busca permanecer eternamente como criança ou jovem" (Homem, 2009, p.4). A autora acrescenta que se observa, no "processo de adolescentização da posição oferecida à subjetividade, o desejo de tudo realizar, sem se colocar na posição de escolha consequente e muito menos de responsabilidade por seus fazeres" (Homem, 2009, p. 5).

A importância dessa questão ultrapassa o âmbito da psicanálise. Como afirmam Pereira e Gurski (2014): "a noção de vaguidade do lugar do adulto, ou ainda, a de que estamos frente a um tempo de adolescência generalizada não é questão apenas para psicanalistas" (Pereira \& Gurski, 2014, p. 377). A professora de antropologia Guita Debert (2010), por exemplo, revela que a valorização da juventude como uma etapa da vida marcada pelo dinamismo e criatividade é bastante recente, bem como a construção da ideia do jovem como um rebelde que se opõe a hipocrisias sociais, pontuando que essas representações aparecem no contexto do pós-guerra. Para a autora, a dissolução da vida adulta nas sociedades contemporâneas apresenta três processos que se encontram inter-relacionados:

(1) o alargamento da faixa etária do segmento considerado jovem da população; (2) o desdobramento das etapas mais avançadas do ciclo da vida em novas categorias etárias; e (3) a transformação da juventude em um valor, que pode ser conquistado em qualquer etapa da vida através da adoção de formas de consumo e estilos de vida adequados. (Debert, 2010, p.49).

A autora nos oferece duas análises desse cenário, uma otimista e outra mais pessimista. Por um lado, cita Giddens (1992), que acredita que "as mudanças estariam abrindo possibilidades para experiências mais gratificantes, para relacionamentos mais satisfatórios e igualitários com os outros" (Debert, 2010, p.64); e, por outro lado, cita Jean-Pierre Boutinet (1995), que propõe a ideia de que a adolescentização equivaleria à substituição da noção de autonomia, que caracterizaria a vida adulta, por uma situação de precariedade e dependência.

Considerando esta tese de que vivemos uma época marcada por uma adolescentização generalizada, perguntamos: Quais seriam os impactos deste cenário na educação formal? O propósito deste artigo teórico-especulativo é refletir sobre a adolescentização e em seguida localizar os impasses que este fenômeno impõe à educação formal.

\section{Adolescentização generalizada: a diminuição do horizonte alteritário}

Francisco "Chico" Anysio de Oliveira Paula Filho (19312012), ator e escritor famoso pelos seus inúmeros quadros em programas humorísticos na Rede Globo, escreveu e encenou um programa semanal intitulado "Chico Anysio Show", exibido no período de 04/03/1982 a 02/08/1990. No ano de 1988, o programa nos apresenta um novo personagem: Jovelino Venceslau dos Santos, ou, simplesmente, Jovem. 
JOVEM - Jovelino Venceslau dos Santos era um rebelde que fazia, com a ajuda do amigo Cabuça (Marcelo Caridad), qualquer coisa para desafiar o sistema, mas ainda vivia sob a superproteção da mãe (Lupe Gigliotti): "Pô mãe, pô... Eu sou jovem! Jovem não dorme, jovem dá um tempo!". A aparência, a voz e o jeito de falar do personagem foram inspirados na interpretação do ator Taumaturgo Ferreira na novela "Mandala" (1987) (Memória Globo, 2013, s. p.).

É surpreendente a agilidade com que o universo da arte capta as transformações sociais. O referido personagem de Chico Anysio retrata posições, afetos e encenações de uma juventude que se mantém no lugar do jovem apesar de todas as contradições. Um diálogo interessante exibido no ano de 1989 revela o desejo pelo impossível, talvez o impossível da fixação do tempo através da metáfora do processo de empalhamento.

Jovem: Nós vamos empalhar este formigueiro.

Mãe: Mas, empalhar um formigueiro deve ser dificílimo.

Jovem: Difícil, não, mãe; é impossível. Mas jovem é assim; jovem gosta das decisões, das missões, das tarefas impossíveis.

Mãe: Mas, tarefa impossível, meu filho, de que adianta?

Jovem: Adianta, mãe, porque depois da gente não conseguir empalhar este formigueiro, a gente vai tentar não conseguir empalhar uma casa de marimbondos e tentar não empalhar um covil de cobras.

Mãe: Meu Deus do céu! Um covil de cobras! Qualquer hora desta você vai querer empalhar sua mãe...

Jovem: Pô, mãe, topa! Vai ser o maior barato... (Sidney \& Vianna, 1989, [s. p.])

Empalhar o impossível. Seria este o desejo de uma geração? Talvez empalhar-se para manter-se eternamente na juventude? É no mínimo curioso que o personagem Jovem tenha sido inspirado em outro personagem veiculado por uma novela que, por sua vez, transportou o mito de Édipo para o Rio de Janeiro do século XX. O personagem de Chico Anysio foi construído a partir das impressões que o humorista recolheu da atuação de Taumaturgo Ferreira como Laio, o pai de Édipo.

Assim, em um deslizamento de significante, passamos do "jovem" para o mito de Édipo. Mas qual é a relação entre juventude e o tema de Édipo? A teoria freudiana nos apresenta o complexo de Édipo como um momento crucial do processo de subjetivação. Ao final das famosas fases descritas pela teoria freudiana, oral, anal e fálica, a criança precisa se posicionar diante das exigências do declínio do amor edípico e entrar em um período de latência no qual se dá o recalque da sexualidade infantil. Todavia, todo este campo pulsional da sexualidade emerge, novamente, com a força da puberdade, que pode ser definida "como fase de amadurecimento sexual das crianças, que marca a transição do corpo infantil para as funções adultas da procriação, tem lugar em todas as culturas" (Kehl, 2007, p. 45).

Mas, ao invés de acentuar a similaridade entre as culturas, é preciso enfatizar a diferença. Segundo Dumont (1980), as sociedades clássicas eram fundadas num ideário holista, ${ }^{1}$ ou seja, a imagem de si integra a totalidade, sua identidade é vivida como a expressão de sua vinculação social. Sendo assim, nestes casos, a responsabilidade sobre o processo de superação da força dilacerante da puberdade sobre o corpo infantil é de todos, e, por isso, a puberdade vivenciada em uma sociedade holista encontra solo no espaço comunitário para realizar a passagem sem grandes dilacerações da alma. As sociedades modernas, por sua vez, baseiam-se no individualismo como ideologia hegemônica: seria possível para os sujeitos viverem sua natureza como sendo de indivíduos, isto é, seres singulares. Livres, autônomos, dotados de mundo interno próprio, morada de sua verdadeira identidade.

Para Boaventura Jr. e Pereira (2015), no caso das sociedades holistas, os ritos de passagem facilitam a tradução da real e concreta modificação corporal em experiência simbólica. Isso é explicado por Kehl (2007):

Da Grécia clássica às sociedades indígenas brasileiras, o/a púbere é reconhecido enquanto tal, e a passagem da infância para a vida adulta é acompanhada por rituais cuja principal função é reinscrever simbolicamente o corpo desse/a que não é mais criança, de modo a que passe a ocupar um lugar entre os adultos. (Kehl, 2007, p. 45).

Já nas sociedades modernas ou individualistas, o sujeito perde esta identidade vivida como expressão do vínculo social, mas ganha autonomia individual. Neste cenário, falta para o púbere um aparato comunitário que suporte as novas exigências pulsionais, que se manifestam em um corpo infantil desajeitado. Como consequência deste novo arranjo, surge a ideia de "adolescência".

O conceito de adolescência é tributário da incompatibilidade entre maturidade sexual e o despreparo para o casamento. Ou, também, do hiato entre a plena aquisição de capacidades físicas do adulto - força, destreza, habilidade, coordenação, etc. - e a falta de maturidade intelectual e emocional, necessária para o ingresso no mercado de trabalho. O aumento progressivo do período de formação escolar, a alta competitividade do mercado de trabalho nos países capitalistas e, mais recentemente, a escassez de empregos obrigam o jovem adulto a viver cada vez mais

\footnotetext{
1 A tese brilhante sobre a passagem de modelo social holista para um individualista foi descrita por L. Dumont (1980). Segundo Renaut (1989), quando Dumont regressa de sua viagem pela sociedade indiana para a França, percebe a diferença de organização $e$, assim, propõe sua teoria. Ver: Renaut. A. (1989). A era do indivíduo. Lisboa: Instituto Piaget.
} 
tempo na condição de "adolescente", dependente da família, apartado das decisões e responsabilidades da vida pública, incapaz de decidir seu destino. Nessas circunstâncias, a adolescência só poderia se tornar uma idade crítica. (Kehl, 2007, p. 45).

O conceito de adolescência surge para oferecer um contorno linguístico para o insuportável das transformações da puberdade que se concretiza em um corpo sem o amparo de uma organização social holista. O sujeito torna-se adolescente, então, na solidão do cenário individualista, no hiato entre a maturidade sexual e a imaturidade emocional.

Mas, se a adolescência se apresenta como um momento de crise, por que surge um movimento social de moratória psicossocial da adolescência? Apenas pela escassez de empregos? Não haveria um ganho psíquico e social em se manter na posição de jovem ou adolescente?

Do ponto de vista social, pode-se afirmar que prolongar a adolescência equivale a manter um estrato específico de consumo por mais tempo. Estando a contemporaneidade marcada pelo individualismo em oposição à tradição, e a construção identitária dos sujeitos não mais encontrando aparato nas transmissões e tradições sociais, o discurso do consumo se revela como uma propensão natural à felicidade, colocando-se como a autêntica salvação da civilização moderna (Baudrillard, 2011). Para Baudrillard (2011), a conduta do consumo, para além das lógicas do objeto e do prazer, traduz um sistema que assegura a ordenação dos signos e a integração do grupo, revelando-se enquanto um sistema de produção não de objetos, mas de estruturação social e de valores morais e ideológicos. "Neste sentido, o consumo constitui uma ordem de significações, como a linguagem, ou como o sistema de parentesco nas sociedades primitivas" (Baudrillard, 2011, p. 92).

Kehl (2007) revela que pesquisas de marketing definiram uma nova fatia de mercado: o jovem. "A partir daí - viva o jovem! Passou a ser considerado cidadão, porque virou consumidor" (Kehl, 2007, p.45). Esta nova condição do jovem de cidadão/consumidor se transformou em uma mina de ouro para as empresas de publicidade:

Ser jovem virou slogan, virou clichê publicitário, virou imperativo categórico - condição para se pertencer a uma certa elite atualizada e vitoriosa. Ao mesmo tempo, a "juventude" se revelava um poderosíssimo exército de consumidores, livres dos freios morais e religiosos que regulavam a relação do corpo com os prazeres, e desligados de qualquer discurso tradicional que pudesse fornecer critérios quanto ao valor e à consistência, digamos, existencial, de uma enxurrada de mercadorias tornadas, da noite para o dia, essenciais para a nossa felicidade. (Kehl, 2007, p. 47).

É interessante ressaltar que nesta citação de Kehl aparecem as palavras "jovem" e "juventude". A partir desta observação, pode-se sugerir que talvez a adolescentização da sociedade ocorra através do processo de hipervaloriza- ção da juventude. A noção de juventude porta aproximações com a experiência adolescente, mas apresenta diminuído o conteúdo de sofrimento. Neste sentido, a possível adolescentização da sociedade tenta fixar as delícias da juventude, transformando a juventude em paradigma de consumo ao mesmo tempo em que transforma o jovem em consumidor.

Como características dessa juventude, podemos pensar na flexibilidade de se encenarem diferentes identidades, num rico horizonte de experimentação da sexualidade, no descompromisso com qualquer posição duradoura, na permanente perspectiva de ruptura, que combina com o estado líquido das relações (Bauman, 2011), e na não responsabilização pelas gerações futuras. Podemos pensar que estas características se apoiam em um possível desmentido (Verleugnung) da castração (Freud, 1929/1976), que pode ser interpretado como uma negação dos limites inerentes à vida.

A teoria freudiana nos revela que a Verleugnung, antes ser um mecanismo fundante da posição sexual fetichista, em que o sujeito elege um único objeto para seu gozo sexual, é um mecanismo comum às crianças que desmente a diferença entre os sexos e pode aparecer na neurose como o desmentido de uma cena traumática (Freud, 1929/1976), ou seja, uma ação psíquica de negar um fato que se apresenta como insuportável ao psiquismo.

Desse modo, um fragmento de realidade, indubitavelmente importante, fora rejeitado pelo ego [Verleugnung], tal como o fato desagradável da castração feminina é rejeitado nos fetichistas. Também comecei a suspeitar que ocorrências semelhantes na infância de maneira alguma são raras. (Freud, 1929/1976, p. 183).

A frase que descreveria a ideia do desmentido seria: "eu vi os limites e as diferenças, mas mesmo assim...". Não estamos dizendo que a adolescentização generalizada da sociedade produz sujeitos perversos ou fetichistas, mas que o arranjo conveniente para a manutenção do consumismo é a ilusão de não haver limites, sejam eles sexuais, identitários, sociais, físicos, ou de outra natureza. Se há disponibilidade de dinheiro para pagar, é só comprar um corpo de Barbie ou Ken. Neste sentido, o valor supremo é o seu eu, ou melhor, o seu corpo e seus prazeres infinitos. Como revela Cintra (2004), as ações da Verleugnung apresentadas no texto freudiano se encontram "em conformidade com o princípio de prazer e com as exigências do desejo e alheia ao complexo de castração" (Cintra, 2004, p.48). A autora prossegue:

Os aspectos desagradáveis da existência são aqueles que desmentem a onipotência: a origem da própria vida ter sido uma decisão alheia a quem nasce, o fato de não ser autônomo e independente afetivamente das outras pessoas e de não ser tão belo, perfeito, inteligente e poderoso como gostaria de ser, de não poder ser tudo para alguém de maneira duradoura e o fato de não poder controlar e possuir, de modo exclusivo e autoritário, a pessoa amada, colocando-a 
sempre a seu dispor, e ainda o fato de não poder ser homem e mulher ao mesmo tempo; tudo enfim que fere o desejo insaciável de absoluto e protege contra a revelação da face de desamparo, dependência e incompletude, evitando a travessia do complexo de castração (Cintra, 2004, p. 48).

Neste sentido, articulamos a ideia da adolescentização generalizada com o mecanismo da Verleugnung, ou seja, o movimento de recusa dos limites, a possibilidade imaginária da total liberdade. Vale, aqui, reiterar a reflexão de Kehl (2007): "o adolescente pós-moderno desfruta de todas as liberdades da vida adulta, mas é poupado de quase todas as responsabilidades" (Kehl, 2007, p. 47).

Enfatiza-se o caráter ilusório de liberdade que a adolescentização generalizada produz. Trata-se não de sujeitos genuinamente livres, enquanto sujeitos autônomos em seus movimentos e ações, e, portanto responsáveis, mas de sujeitos presos em uma lógica que reproduz a ilusão de que a liberdade se traduz pela abundância dos objetos e pela capacidade individual de aquisição dos mesmos. A contemporaneidade, marcada pelo individualismo e pela lógica do consumo, nega a interdependência entre os sujeitos e a necessidade da socialização e do reconhecimento do outro como essencial à própria existência do eu. Ainda que o consumo ajuste os sujeitos a um código coletivo, a socialização pelos objetos os isola, pois incide na individualidade e nega qualquer solidariedade coletiva.

A recusa a limites não se exprime pela ânsia de liberdade, já que os sujeitos contemporâneos, na verdade, não são livres. Ainda que neguem as responsabilidades da vida adulta, continuam servos dos objetos. A recusa que fazem é pelo limite do outro, pela alteridade; o outro é visto não como sujeito a ser reconhecido, mas enquanto ameaça à satisfação ilimitada do eu.

Bauman (2011), citando Tocqueville, aponta que o indivíduo é o pior inimigo do cidadão, pois enquanto o cidadão tende a buscar seu próprio bem-estar através do bem-estar da cidade, o indivíduo tende a ser cético em relação ao bem social comum, enxergando o campo público apenas como um lugar que serve para garantir a segurança de suas posses e a realização das próprias satisfações. Assim, o espaço público é ocupado não pelas questões públicas, mas pelo campo do privado, sendo tomado pelas questões individuais.

Para Lasch (1983), tal cultura narcísica - assinalada pela paixão pelo presente e por preocupações de âmbito puramente pessoais - marca um enfraquecimento do sentido político e temporal histórico. O caráter narcisista da contemporaneidade enfraquece a noção de coletividade ao enfatizar um ideal de responsabilidade que concerne apenas ao individual. Segundo o autor, na cultura narcísica, "as pessoas percebem sua posição social como um reflexo de suas próprias capacidades", e "a política se degenera em uma luta não para a mudança social, mas para a autorrealização" (Lasch, 1983, p.51).

Esta ideia da não responsabilização encontra subsídios também na teoria psicológica de Erikson (1950/1998), que afirma ser o último conflito da juventude a polarização entre a coragem de entrar em uma relação íntima e o movimento do isolamento. A resolução de tal conflito deve ser marcada pela capacidade do indivíduo de aceitar a convivência com outro ego sem sentir-se ameaçado. Para que tal associação seja positiva, Erikson aponta como requisito a existência de um ego forte e autônomo, pois, ao contrário, o sujeito irá preferir o isolamento à união, de maneira a preservar seu ego frágil.

O conflito seguinte, denominado por Erikson como Generatividade x Estagnação, marca o fim da juventude e o início da vida adulta. Segundo o autor, nesta fase o indivíduo se preocupa em gerar - no sentido de produzir algo - e com o cuidado com o que foi gerado. Isso diz da necessidade humana de transmissão, que reflete a ideia de se fazer sobreviver através das próprias obras e ensinamentos e marca a responsabilidade para com o outro e com a humanidade. Caso esta transmissão não ocorra, o indivíduo irá se deparar com um vazio de sentido em relação à própria existência, devido à impossibilidade de continuidade sobre tudo o que foi até então construído.

Lasch (1983), ao realizar uma análise da literatura clínica, buscando características que pudessem dizer algo sobre o narcisismo enquanto fenômeno social, afirma que os pacientes que se apresentavam para tratamento psicológico a partir dos anos 1940 e 1950 em pouco lembravam as neuroses clássicas descritas por Freud, mas se queixavam de "insatisfação difusa e vaga com a vida, sentimento de que sua existência amorfa é fútil e sem finalidade; sentimentos de vazio e depressão, oscilações de autoestima e incapacidade geral de progredir" (Lasch, 1983, pp.61-62).

Neste sentido, Lasch (1983) parece descrever sujeitos que, ingressos na vida adulta, não conseguem estabelecer uma relação de responsabilidade com o outro, estagnando suas identidades em um ideal fantasmático de juventude, buscando viver os prazeres do amor líquido (Bauman, 2011), que não exige nem o reconhecimento nem a responsabilidade com o outro. Nesse contexto, o outro, identificado pela lógica do consumo, é tido apenas como objeto, facilmente substituível, e destinado apenas ao prazer.

Outro elemento que pode favorecer a fixação na juventude é a relação que a sociedade contemporânea estabelece com o tempo. Sabemos que a ruptura com a dimensão das tradições é uma das características da passagem da sociedade pré-moderna para a moderna. Renaut (1998) revela que "o traço mais específico das sociedades modernas é a contínua dissolução das referências oriundas do passado" (Renaut, 1998, p. 31). Isso marca uma diferença entre comportamentos: se na pré-modernidade "o homem... busca no passado referências normativas para seu presente" (Moreira, Rosário, \& Santos, 2012, p.460), a partir do período moderno o homem passa a apostar no futuro, buscando nele as referências normativas de sua vida.

Fundamentados nestes apontamentos, podemos pensar que os homens pré-moderno e o moderno, ainda que com focos diferentes, se situam ambos na trama temporal da história, na certeza do movimento limitador do tempo. Já o homem pós-moderno pode ser caracterizado pela ruptura 
com o fluxo temporal e a fixação no presente. Moreira e cols. (2012) propõem

uma articulação entre a valorização do tempo do presente na atualidade com o domínio do desejo de manutenção da juventude... Pensamos que a juventude é exatamente o momento do presente, pois se rompe com o passado, representado pela família, e se lança em uma ilusão de imortalidade e onipotência que não percebe o futuro como um limite (Moreira \& cols., 2012, p.461).

Nessa perspectiva, o jovem vive intensamente o hoje no palco do seu próprio corpo. Podemos pensar em uma força centrípeta que direciona os investimentos para dentro do eu, esvaziando, pois, o campo de investimento e reconhecimento do outro.

A teoria psicanalítica propõe a expressão "narcisismo das pequenas diferenças" para dizer desta percepção da diferença e da alteridade enquanto uma ameaça à integridade narcísica do eu. Podemos dizer que é justamente nas pequenas diferenças, não obstante as semelhanças em todo o resto, que se fundamentam os sentimentos de estranheza e hostilidade entre desconhecidos. Para a psicanálise, é deste "narcisismo das pequenas diferenças" que deriva a hostilidade inerente aos vínculos humanos, em oposição aos imagináveis sentimentos de solidariedade e amor ao próximo. Neste sentido, o narcisismo se opõe ao reconhecimento do outro enquanto alteridade, e a diferença é colocada enquanto uma ameaça ao eu. Assim, o reconhecimento do outro se encontra não na aceitação das diferenças, mas condicionado à negação da alteridade.

Em "Mal-estar na civilização", Freud (1930/1996) enfatiza o imperativo do vínculo social como uma das fontes de sofrimento dos sujeitos. A civilização, por exigir que o sujeito abdique de parte de sua satisfação pulsional em prol de si mesma, se apresenta para Freud como umas das principais causas de sofrimento do eu. Contudo, ainda que mediante o sacrifício de parte da satisfação e da liberdade, é a própria civilização que garante ao sujeito segurança e condições de sobrevivência. A condição da vida humana é sua própria precariedade, sua vulnerabilidade, e sua condição precária implica viver socialmente. Dessa forma, ainda que a vida em sociedade se coloque como a fonte de todo mal, é também fundamental para a garantia da existência do eu.

Contudo, ao enviar os sujeitos a outra lógica de sociabilidade, pautada pelo individualismo em detrimento da solidariedade para com a coletividade, a sociedade do consumo produz um imaginário em que não é mais necessário abdicar da liberdade e das satisfações, assim como não é necessário reconhecer a alteridade, pois tudo se traduz pelo acesso aos objetos. Vende-se a segurança sem que se sacrifique a liberdade; vende-se a felicidade sem que se sacrifique a satisfação prazerosa. Reconhecem-se apenas os iguais e nega-se a alteridade, não sendo mais necessário sentir-se responsável pelo outro.

Esta nova configuração social que apresenta uma possível adolescentização generalizada anuncia desafios para o processo da educação formal. Como se pode educar um jovem hoje?

\section{Educação e adolescentização: desafios e possibilidades}

Antes de se discutir a relação entre educação e adolescentização, faz-se necessário definir "educação". Um caminho possível é buscar as raízes etimológicas da palavra para apreender os ideais que circulam em torno do conceito. Segundo Sampaio e Mesquita (2002) a palavra "educação" tem origem em termos latinos, tais como os verbos educare e educere. O verbo educere é derivado de ex-ducere, "que significa, literalmente, conduzir (à força) para fora"; e educare "significa amamentar, criar, alimentar"(Sampaio, Santos, \& Mesquita, 2002, p. 1). Assim, o significante "educação" carrega duas propostas: de um lado, conduzir o sujeito para fora de si, ou seja, em direção ao outro, podendo este outro ser pensado como a humanidade; de outro, alimentar o sujeito, nutrir e criar uma vida humana, uma nutrição que ultrapassa o alimento biológico.

A segunda acepção da palavra "educação", que se refere à ação de nutrir, não apresenta contradições com o novo cenário de hipervalorização da posição de jovem/adolescente. Na verdade, podemos pensar que a adolescentização generalizada favorece a ideia de um sujeito esperando o alimento para se nutrir. Podemos pensar que um projeto educativo que pode representar o modelo da nutrição é a proposta conteudista, ou outra proposta que privilegie a educação técnica em detrimento da formação humana. Reconhecemos a importância dos dois projetos - a proposta conteudista e a formação tecnológica -, mas ressaltamos que estas podem se distanciar da ideia de educação como saída para fora de si.

A noção de educação como saída de si é um movimento em direção ao outro. Pode se apresentar, portanto, como uma tarefa impossível. Considerando-se que na adolescentização generalizada o campo alteritário se encontra eclipsado, como formar/educar cidadãos com capacidade de se responsabilizar pelo o outro? Não podemos negar que este ideal de educação foi construído no seio de uma sociedade holista, ou seja, em um espaço em que o projeto individual se encontra fortemente submetido ao todo social. Uma organização social individualista apresenta mais dificuldades de sustentar o ideal de educação como uma proposta de subordinação dos desejos individuais em prol do projeto coletivo. Mas, mesmo em uma sociedade individualista, é preciso transmitir este valor como forma de sustentação da humanidade, ainda que isto seja mais conflituoso.

Pensando no cenário moderno, podemos arriscar a hipótese de que o ideal de educação mantém o anterior, mas com o acréscimo das diretrizes iluministas. Assim, é preciso educar para a liberdade, igualdade e fraternidade. Santos (2001), citando Karl Jaspers (1923), anuncia que a universidade deve ser um espaço que, por concessão do Estado e da sociedade, cultiva uma lúcida consciência de si próprio. 
Compreendemos que a proposta de Jaspers se articula com a perspectiva fenomenológica da defesa de uma consciência intencional que se relaciona com o mundo através do desvelamento do fenômeno, sendo, assim, fundamental defender a ideia de uma lúcida consciência de si próprio. Entretanto, se considerarmos as contribuições freudianas para pensar o sujeito e a cultura, sabemos que é difícil realizar o projeto de lúcida consciência de si.

Seguindo com Jaspers (1923, citado por Santos, 2001), Santos (2001) revela que a universidade responde a três grandes objetivos: a investigação, a produção de cultura e a transmissão de conhecimento. Mas, segundo o autor, no final do século $X X$, a universidade recebeu novos desígnios:

Educação geral pós-secundária; investigação; fornecimento de mão de obra qualificada; educação e treinamento altamente especializados; fortalecimento da competitividade da economia; mecanismo de seleção para empregos de alto nível através da credencialização; mobilidade social para os filhos e filhas das famílias operárias; prestação de serviços à região e à comunidade local; paradigmas de aplicação de políticas nacionais (ex.: igualdade de oportunidades para mulheres e minorias raciais); preparação para os papéis de liderança social. (Santos, 2001, p. 189).

Considerando a interpretação de Santos (2001), Guerra, Moreira e Romagnoli (2005) enfatizam a articulação entre educação e mobilidade social. Nas palavras das autoras:

É interessante perceber que foi atribuída à universidade a tarefa de cumprir o ideário iluminista e liberal de igualdade. Mas é importante ressaltar que o pressuposto da igualdade é a diferença; só se pode desejar ser igual a alguém porque se é diferente. (Guerra \& cols., 2005, p.91).

Pensamos que a educação assentada no tripé liberdade, igualdade e fraternidade, em tempos de adolescentização generalizada, pode sobrecarregar a transmissão do ideário de liberdade em detrimento do projeto da fraternidade,o que poderia alimentar ainda mais uma posição narcisista e egoísta. Por outro lado, a importante discussão da igualdade de direitos pode ser deturpada no sentido de negar as diferenças, produzindo, pois, um projeto de educação que não transmite o valor de respeito ao outro enquanto um diferente.

\section{Considerações finais}

“A 'adolescentização' das etapas mais avançadas da vida tem servido para indicar uma nova configuração social na qual a diferença de idades e a própria ideia de ciclos da vida parecem perder significado" (Debert, 2010, p. 52). As tradicionais características atribuídas à vida adulta parecem não mais fazer sentido em uma sociedade que, mediada por imagens, encontra na juventude um de seus valores fundamentais, fazendo da juventude mais que uma mercadoria a ser adquirida. A juventude passa a ser um ethos da contemporaneidade.

O ideal de juventude, para além do referencial imagético, se mostra como um conceito fundamental da modernidade, pois produz sujeitos que, em uma constante crise identitária, buscam diferenciar-se e afirmar suas identidades através do consumo e dos objetos. Se a condição de adulto diz da liberdade - enquanto autonomia e responsabilidade sobre as próprias ações -, do reconhecimento do outro e da inscrição na vida pública, tal condição encontra-se na contramão de uma sociedade que se pauta pelo individualismo, produzindo, pois, uma precariedade nos laços sociais. Butler (2015), ao afirmar a precariedade da vida, enfatiza a necessidade do reconhecimento. Toda vida é precária, e a socialização se faz necessária para a própria sobrevivência. Freud, ainda que aponte um impasse ao reconhecimento ao elaborar o conceito de narcisismo das pequenas diferenças, também afirma a necessidade da civilização, que não é promessa de felicidade, mas de sobrevivência. A política não se traduz pela ocupação do espaço público para a realização das satisfações individuais, mas pela necessidade de se abdicar de parte da própria satisfação em prol do bem comum. O discurso do consumo propaga a resolução de tal impasse, criando a fantasia da completude pelos objetos, e, nessa perspectiva, a vida adulta se dissolve pela liberdade que lhe é característica. O que se deseja não é liberdade, mas a condição de não ser responsável.

Tal cultura do eu em detrimento do outro se reflete, obviamente, nos processos educacionais. Pela influência do sistema econômico capitalista e da globalização, a educação tem se fundamentado nas problemáticas da produtividade e da competitividade - nas quais os processos de conhecimento e aprendizagem são guiados por sua utilidade econômica imediata - em oposição à noção de direitos e cidadania. Assim, por fundamentar-se na formação do indivíduo enquanto capital humano, o processo educacional de lógica mercadológica tende também a minar a solidariedade e a organização coletiva, uma vez que se pauta na produtividade individual e na competitividade. O Estado de bem-estar dá lugar ao Estado do Consumo, em que a organização social se baseia não mais no bem comum, mas na capacidade individual dos sujeitos de se doarem enquanto capital humano.

Baudrillard (2011), ao dizer da lógica social do consumo enquanto um processo de classificação e de diferenciação social, aponta para o consumo dos objetos não pelo seu valor de uso, mas enquanto signos de distinção social. Ao transformar o processo educacional em mercadoria, a sociedade de consumo objetifica a educação, que passa a ser utilizada como mecanismo de distinção e estratificação social, em detrimento dos ideais de igualdade e fraternidade, ou seja, em contraposição à noção de reconhecimento e de cidadania. A educação na era do ethos da adolescentização generalizada também serve ao consumo, tornando-se mais um elemento de elevação dos níveis de desigualdade e exclusão social. 


\section{Referências}

Baudrillard, J. (2011). A sociedade de consumo. Lisboa: Edições 70.

Bauman, Z. (2011). Modernidade Líquida. Rio de Janeiro: Jorge Zahar.

Boaventura Jr., M. \& Pereira, M.R. (2015). "Lá fora... Na rua é diferente!": adolescência, escola e recusa. Curitiba: Editora Appris.

Butler, J. (2015). Quadros de guerra: quando a vida é passível de luto? Rio de Janeiro: Civilização Brasileira.

Cintra, E.M.U. (2004). A questão da crença versus a questão da fé: articulações com a Verleugnung freudiana. Psicologia em Revista, 10(15), 43-56.

Debert, G.G. (2010). A dissolução da vida adulta e a juventude como valor. Horizontes Antropológicos, 16(34), 49-70.

Dumont, L. (1980). O individualismo: uma perspectiva antropológica da ideologia moderna. Rio de Janeiro: Rocco.

Erikson, E.H. (1998). Oiclo de vida completo. Porto Alegre: Artmed. (Trabalho original publicado em 1950).

Freud, S.(1976) Fetichismo. Em J. Strachey (Org.), Edição Standard Brasileira das obras psicológicas completas de Sigmund Freud. (J. Strachey, Trad.) (Vol. 21, pp.175-187). Rio de Janeiro: Imago. (Trabalho original publicado em 1929).

Freud, S.(1996) O mal-estar na civilização. Em J. Strachey (Org.), Edição Standard Brasileira das obras psicológicas completas de Sigmund Freud. (J. Salomão,Trad.) (Vol. 21, pp. 75-174). Rio de Janeiro: Imago. (Trabalho original publicado em 1930).

Frois, E., Moreira, J.O., \& Stengel, M. (2011). Mídias e a imagem corporal na adolescência: o corpo em discussão. Psicologia em Estudo, 16(1), 71-77. Recuperado: 08 jan. 2016. Disponível: http://www.scielo.br/scielo.php?script=sci_arttext\&pid=S141373722011000100009\&lng=pt\&tlng=pt.
Guerra, A.M.C., Moreira, J.O., \& Romagnoli, R.C. (2005) A crise subjetiva na universidade: perspectivas e desafios contemporâneos. Mental, 3(5), 91-113.

Homem M. L. (2009) A criança eterna. Rev Facom, 21, 28-34. Recuperado: 08 jul. 2016. Disponível: http://www.faap.br/revista_ faap/revista_facom/facom_21/maria.pdf

Kehl, M.R. (2007). A juventude como sintoma da cultura. Outro Olhar,5(6), 44-55.

Lasch, C. (1983). A cultura do narcisismo. Rio de Janeiro: Imago.

Memória Globo (s.d.). Chico Anysio Show. Recuperado: 05 jan. 2016. Disponível: http://memoriaglobo.globo.com/programas/ entretenimento/humor/chico-anysio-show/galeria-depersonagens.htm.

Moreira, J.O., Rosário, A.B., \& Santos, A.P. (2012). Juventude e adolescência: considerações preliminares. Psico, 42(4), 457-464.

Pereira, M.R. \& Gurski, R. (2014). A adolescência generalizada como efeito do discurso do capitalista e da adultez erodida. Psicologia \& Sociedade, 26(2), 376-383.

Renaut. A. (1989). A era do indivíduo. Lisboa, Instituto Piaget.

Sampaio, C.M.A., Santos, M.S., \& Mesquida, P. (2002). Do conceito de educação à educação no neoliberalismo. Revista Diálogo Educacional, 3(7), 165-178.

Santos, B.S. (2001). Da idéia de universidade à universidade de idéias. Em B. S. Santos (Org.), Pela mão de Alice: o social e o político na pós-modernidade (pp. 187-233). São Paulo: Cortez.

Sidney, E. \& Vianna, Z. (1989). Chico Anysio Show. Recuperado: 05 jan. 2016. Disponível: https://www.youtube.com/ watch?v=ytSLORLwhns.

\section{Sobre as autoras}

Jacqueline de Oliveira Moreira (jackdrawin@yahoo.com.br)

Doutora em Psicologia Clínica PUC SP, Professora do Programa de Pós-Graduação em Psicologia da Pontifícia Universidade Católica de Minas Gerais - PUC Minas - Belo Horizonte- MG, Bolsista PQ 2 CNPq.

Nathiéle Araújo Oliveira (nathiele@task.com.br)

Mestre em Psicologia pela Pontifícia Universidade Católica de Minas Gerais - PUC Minas - Belo Horizonte - MG. 